Arch. Dis. Childh., 1964, 39, 630.

\title{
THE USE OF AN ELASTIC BAND TO PREVENT HAEMORRHAGE FROM THE UMBILICAL CORD
}

\author{
BY
GERALD A. NELIGAN, J. MICHAEL PARKIN, and CHRISTINE PAUL
From the Princess Mary Maternity Hospital, and the Department of Child Health in the University of Newcastle upon Tyne

(RECEIVED FOR PUBLICATION MAY 11, 1964)

When describing the effectiveness of a plastic clamp in eliminating the risk of haemorrhage from the umbilical cord, as compared with the ineffectiveness of standard umbilical tape in some $75^{\circ} \%$ of instances under laboratory conditions, Neligan and Smith (1963) suggested that the use of a rubber band merited further study. This was on account of the clamp's cost, its rather startling appearance in some mothers' eyes, and the need to remove it before the cord became too gangrenous. During further clinical trials we encountered two cases in which the clamp slipped off the end of the cord stump within an hour or two of being applied. This accident caused no harm to the babies concerned, but caused the manufacturers to improve the design of the clamp's jaws-and accelerated our investigation of the use of a rubber band.

D. A. J. Williamson (1963, personal communication) had kindly described to us a method of using a commercial elastic band, as supplied by stationers, which had been used in his unit for some years. We began by investigating this method, with particular reference to the most suitable type of band, its effectiveness when tested in the laboratory, the technique of applying it to the cord, and its clinical use.

\section{Results}

The Elastic Band. Of various samples tested, the most suitable proved to be a flat elastic band made of pure rubber (BB 28).* Its width is $0 \cdot 125$ in. $(0 \cdot 3$ $\mathrm{cm}$.), and its length when laid flat is $1.5 \mathrm{in} .(3.75 \mathrm{~cm}$.), giving a circumference of 3 in. $(7 \cdot 5 \mathrm{~cm}$.). When stretched by suspending a weight of $15 \mathrm{oz}$. (420 g.) the length of different samples increased to a mean of 3.3 in. $(8 \cdot 25 \mathrm{~cm}$.) and none snapped after being continuously stretched for up to one month. When

- Manufactured by Berrick Bros. Ltd., 20-24 Kirby Street, London E.C.1. released, they reverted to approximately their original length. These properties were not altered by immersion in a $1: 500$ solution of cetrimide for up to 14 weeks, nor by being heated in an autoclave at $250=$ F. $(120=$ C. $)$ for 30 minutes. Before being sterilized for clinical use, the bands were rinsed with tap-water to free them of their light covering of talc powder.

Laboratory Testing. 100 segments of fresh cord, whose vein had been flushed free of blood soon after delivery, were occluded with a BB 28 band in the manner to be described, and were left exposed at normal room temperature and humidity. Each was tested by subjecting the vein to a hydrostatic pressure of up to $120 \mathrm{~cm}$. of water, as described by Neligan and Smith (1963), at the start and again after an interval of 24 hours. There was a leak past the band at the start in the narrowest cord tested, from a baby weighing $1 \mathrm{lb}$. (450 g.): but we found that this could be prevented by applying the band more tightly (with five twists instead of four). In the remaining 99 segments no leak occurred, either at the start or after 24 hours of shrinkage of the cord.

Technique of Application. We started by using dissecting forceps to transfer the band, twist by twist, from the closed jaws of a pair of artery forceps onto the cord stump. But we found in the laboratory that there was a tendency for the band to be damaged by the points of the dissecting forceps, and in a clinical trial that the process of transfer was often difficult and frustrating, and that, once on the cord, the band was very tight and difficult to move into the desired position relative to the skin margin. We eventually worked out a technique, using a loop of standard umbilical tape to effect the transfer, which does not risk damaging the band, is easy to carry out in practice, and gives good control over its ultimate position on the cord stump. 


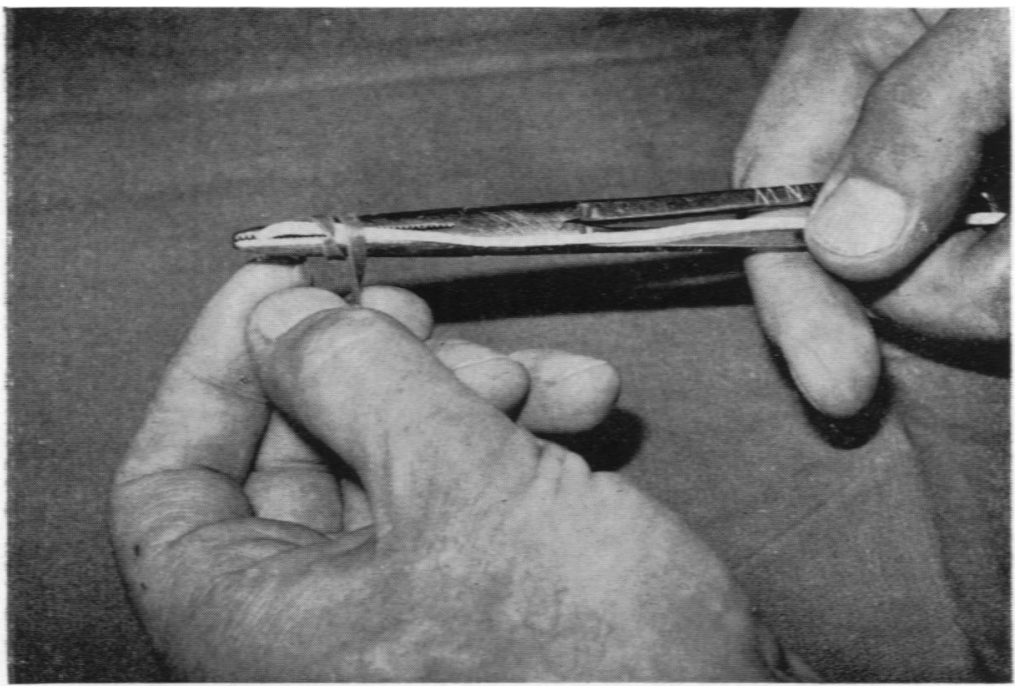

FIGs. 1 and 2.-Technique of 'loading' forceps with elastic band.

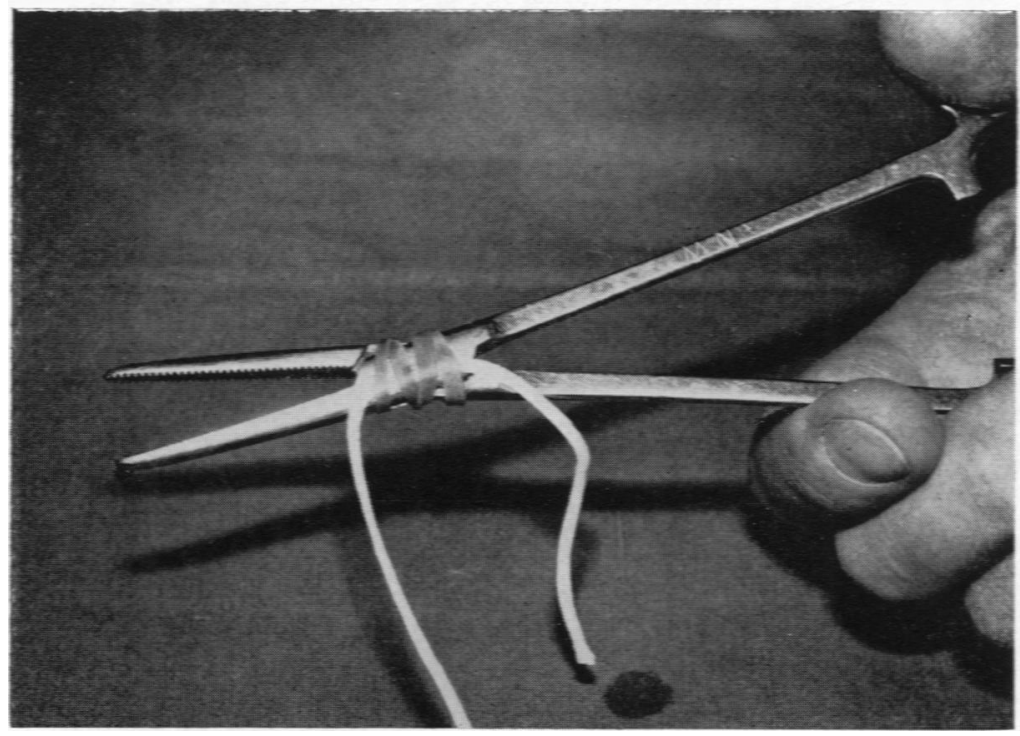

(1) The large pair of artery forceps (7 in., 17.5 cm.) used to clamp the cord initially is removed and the jaws are closed onto the end of a sterile piece of umbilical tape of about the same length. While one hand holds the forceps with the tape lying along the handles, the other hand is used to twist the wet elastic band four times around the closed jaws (and the tape). The jaws are then opened, the tape pulled through to make a loop with two equal limbs, and the band is slid along to lie over the hinge of the forceps (Figs. 1 and 2).
(2) The jaws of the forceps, 'loaded' in this way, are closed onto the cord, crushing it, 0.5 to 1 in. $(1 \cdot 25-2 \cdot 5 \mathrm{~cm}$.) from the skin margin. The surplus cord is cut off alongside the jaws. The loop of tape is used to lift the band, all four twists at once, over the tips of the jaws onto the cord, and into the desired position, which is right up against the skin margin. No harm is done if one or two twists actually overlap the skin. Finally, one end of the tape is released, and it is gently pulled out from under the band before the forceps are removed (Figs. 3 and 


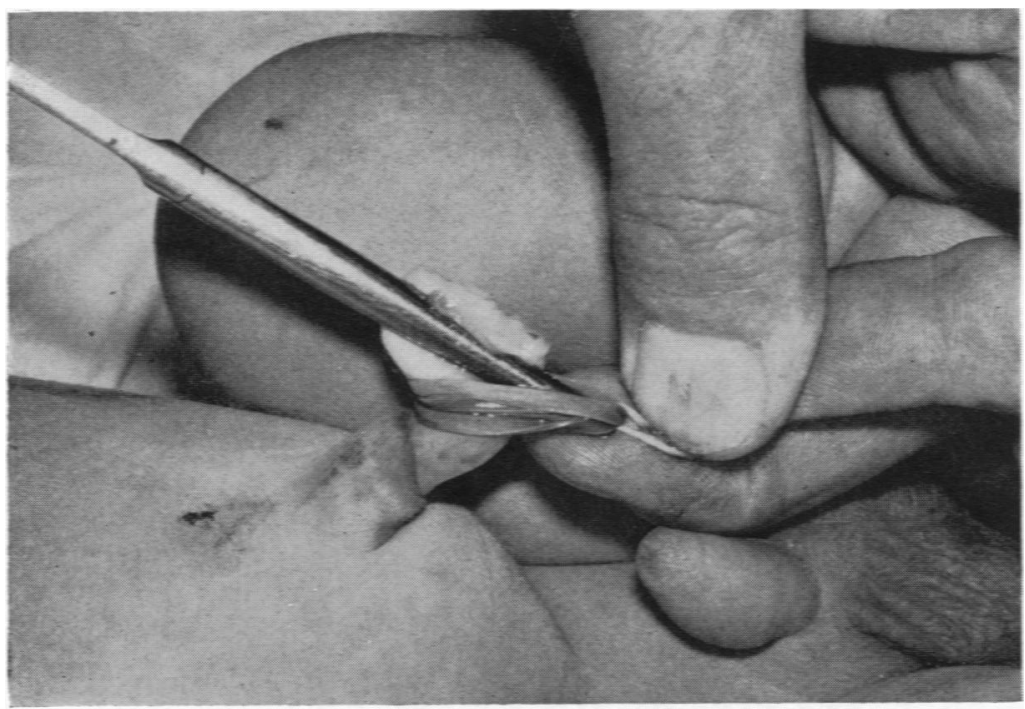

FIGS. 3 and 4.-Technique of transferring elastic band to the cord stump.

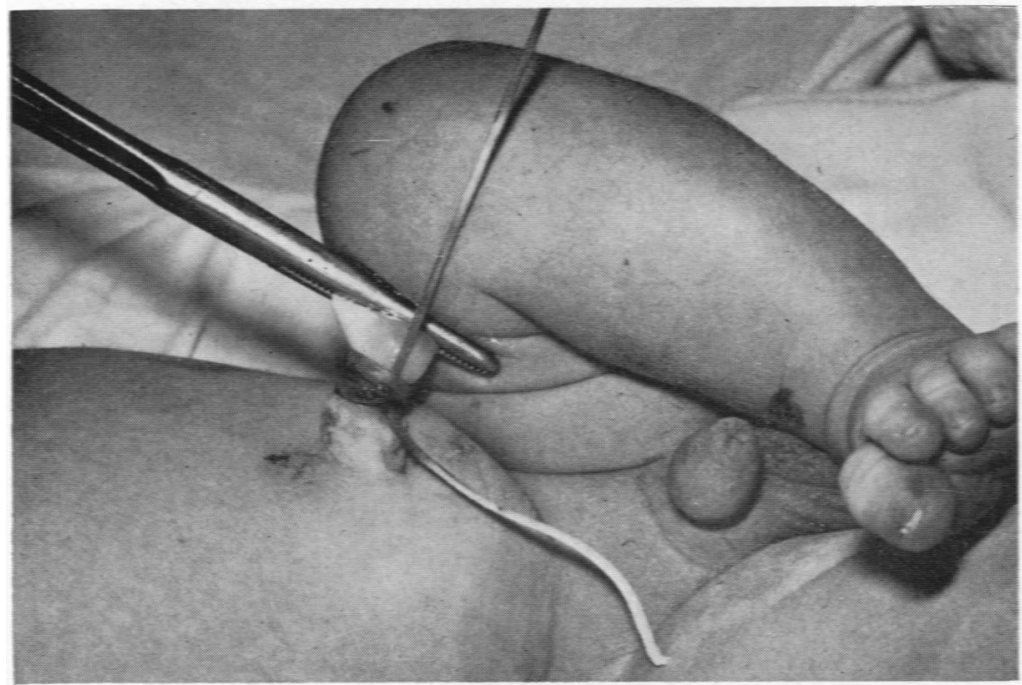

4). The band is left in place until the cord stump separates in the usual way.

The one difficulty that we have encountered is in the rare (but important) case where the cord is much thicker than usual. The pull required to transfer the four twists of band simultaneously may be sufficient to make it cut into the cord. Our laboratory tests have shown that this difficulty should not be dealt with by applying the band more loosely (three twists) since such cords shrink to the same size as others, rendering a loose band ineffective. In such cases we 'load' the forceps with two lengths of tape, in such a way that the band can be transferred in two stages, two twists at a time, with satisfactory results. Alternatively, for those who prefer not to attempt this rather more difficult manoeuvre, we have available a sterile Hollister clamp, of the improved design, which can be applied perfectly easily however thick the cord may be.

Clinical Use. The BB 28 band, applied by the technique described, has proved satisfactory in 1,200 
consecutive babies so far. Two incidental points of practical interest have been noticed.

(a) Separation of the cord stump is hastened, as compared with the use of a tape ligature. The mean age at the time of separation in 30 babies whose cord had been occluded with an elastic band was $6 \cdot 8$ days (standard deviation 4.9); in 29 babies where it had been ligated with tape the mean was 10.4 days (standard deviation 4.4). This difference is highly significant $(\mathrm{t}=2 \cdot 95, \mathrm{p}=0.01)$.

(b) Moistness of the cord stump, at the point of ultimate separation, was greater than with the use of tape, presumably because of the fact that the band is made of non-absorbent material. Cord stumps were left exposed, and cleaned daily with a swab soaked in $0.5 \%$ chlorhexidine in spirit. In case this moistness might imply an increased risk of staphylococcal infection, we retrospectively worked out the incidence of clinical lesions in two groups of babies who had been nursed alongside each other in the same wards, with the results shown in the Table. The longer

TABLE

CLINICAL LESIONS

\begin{tabular}{llllcc}
\hline & & \multicolumn{2}{c}{ Cord Occluded With } \\
\cline { 5 - 5 } & & & Standard Tape & Elastic Band \\
\hline Number of babies & $\ldots$ & $\ldots$ & $\ldots$ & 100 & 100 \\
Mean stay (days) & $\ldots$ & $\ldots$ & $\ldots$ & 7 & 10 \\
Cases of pustule & $\cdots$ & $\ldots$ & $\ldots$ & 3 & 0 \\
Cases of conjunctivitis & $\ldots$ & $\ldots$ & 7 & 17 \\
\hline
\end{tabular}

mean duration of stay in hospital in the elastic band group is explained by the fact that during this trial period only the paediatrician was using this method, and he was present only at complicated or abnormal deliveries. The higher incidence of conjunctivitis in this group appears to be due to the longer period of observation in hospital.

\section{Discussion}

The importance of using a method of cord occlusion which will be fully effective in the rare instances where the natural mechanisms of haemostasis fail needs no further emphasis. Since the report by Neligan and Smith (1963) another instance has come to our notice of a death due to haemorrhage from a cord that had been ligated (by a very experienced person) with standard umbilical tape. This was a normal mature baby with an unusually thick cord, treated with special care.

The crux of the problem of effective haemostasis in this context is the shrinkage of the cord during the first 24 hours of life, which is the danger period.
The ideal requirements for the purpose seem to be met by a strong elastic band, given a satisfactory technique of applying it sufficiently tightly. Current interest in the problem is illustrated by the publication of three methods employing this principle since our investigation was started. Hanson (1963) used 'a $\frac{1}{4}$-inch rubber band cut from conventional intravenous tubing'. We have tested bands cut from the standard intravenous tubing available in this country, and found them easy to apply, using the method described, but ineffective in preventing leaks when tested by our laboratory method after normal shrinkage of the cord. Betheras (1963) and Averbach and Hoffmeier (1964) have described methods involving the use of a special latex band. We have not tested them because they also involve the use of special instruments.

The method described here uses only equipment that is routinely available, apart from the elastic bands whose cost is negligible. The technique of application has been learnt easily by midwives and medical students. Clinical trial in 200 babies with satisfactory results has been followed by routine use of the method in our hospital, in 1,000 babies so far. The very occasional exceptionally thick or exceptionally thin cord calls for minor modifications of the technique, as described. Earlier separation of the stump appears to be an unforeseen advantage of the method.

\section{Summary}

A simple technique is described that makes it possible to apply a commercially available elastic band to the cord stump following birth, sufficiently tightly to ensure effective haemostasis during the first 24 hours of life. The technique can be slightly modified to deal with exceptional cords. The method has been subjected to laboratory and clinical testing, and found satisfactory. Separation of the cord stump is accelerated, and the incidence of clinical infection is not increased.

We are glad to acknowledge the support of the Endowment Fund of the United Newcastle upon Tyne Hospitals, from which C.P.'s salary was paid throughout this investigation.

\section{REFERENCES}

Averbach, L. H., and Hoffmeier, C. L. (1964). A new automatic umbilical-cord bander. Obstet. and Gynec., 23, 146.

Betheras, F. R. (1963). Ligation of the umbilical cord. Lancet, 2, 921.

Hanson, W. N. (1963). A simple method for banding the umbilical cord. Obstet. and Gynec., 22, 513.

Neligan, G. A., and Smith, M. C. (1963). Prevention of haemorrhage from the umbilical cord. Arch. Dis. Childh., 38, 471. 